\title{
AIDS, Clinical Trials on Patients with Opportunistic Infections
}

National Cancer Institute

\section{Source}

National Cancer Institute. AIDS, Clinical Trials on Patients with Opportunistic Infections. NCI Thesaurus. Code C15766.

Clinical trials related to the development of vaccines and therapeutics directed against opportunistic infections associated with HIV infection. These trials include the following opportunistic infections: pneumocystosis, toxoplasmosis, cryptosporidiosis, candidacies, cryptococcosis, mycobacteriosis, cytomegalovirus, papillomavirus, herpes simplex, JC virus, coccidioides, hairy leukoplakia, and HIV-related periodontal disease. 